\title{
VAN DYCK: NOTICIAS SOBRE LOS RETRATOS ECUESTRES DE FRANCISCO DE MONCADA, MARQUÉS DE AYTONA, Y SU PROCENDENCIA EN EL SIGLO XVII
}

En las salas de pintura flamenca del Museo del Louvre se exhibe un magnífico retrato de Van Dyck de grandes dimensiones, en el que un general español, Don Francisco de Moncada, Marqués de Aytona, cabalga sobre un caballo blanco de frente al espectador [Fig. 1] ${ }^{1}$. Es conocido que el cuadro llegó a París en 1798, procedente de la colección del príncipe Braschi de Roma²; pero existe un vacío en cuanto a su origen, pues se desconoce el destino anterior de este importante retrato de gran tamaño y excelente en calidad, considerado por muchos como uno de los más elegantes retratos ecuestres de Van Dyck.

Recorriendo la documentación vinculada al coleccionismo español de los siglos XVII y XVIII, en el transcurso de nuestra investigación para el estudio de la obra de Van Dyck en España, hemos hallado algunas noticias que nos permiten precisar su procedencia más remota en la colección del Marqués del Carpio y Eliche, una de las más prestigiosas en la Europa del siglo XVII. Trataremos

${ }^{1}$ Lienzo, 307 x $242 \mathrm{~cm}$. París, Museo del Louvre [Inv. 1240]. Véase la bibliografía al respecto: Lavallée, J., Galerie du Musée Napoléon, IV, pl. 275 ; Smith, J., A Catalogue Raisonné of the most eminent Dutch, Flemish and French Painters, Londres 1831-1842, $n^{\circ}$ 143; VILLOT, Notice des tableaux exposés dans les galeries du Musée National du Louvre, $2^{\text {ème }}$ partie, écoles flamande et holandaise, Paris, 1852, p. 146, p. 75; Mémoires du comte Horace de Viel-Castel sur le règne de Napoléon III, pp. 161-162 ; Cust 1882, p. 155 ; Guiffrey, J., Anthonie van Dyck et son oeuvre, París, 1882, $\mathrm{n}^{\circ}$ 700a, p. 271 ; Cust, L., Anthony van Dyck. A Historical Study of His Life and Works, Londres, 1900, p. 258 , nº 83 ; Fierens-Gevaert, H., Van Dyck, París, 1904, p. 72; Shaëffer, E., Van Dyck. Des Meisters Gemälde, Klassiker der Kunst, Stuttgart-Leipzig, 1909, p. 318 ; Demonts, L., Musée National du Louvre. Catalogue des peintures Écoles du Nord, París, 1922, $\mathrm{n}^{\circ}$ 1971, p. 31 ; Notice des expositions française et flamande, germinal an VII, n 244, p. 59 ; Glück, G., Van Dyck. Des Meisters Gemälde in 571 Abbildungen, Klassiker der Kunst, Stuttgart-Berlin, 1931. p. 420; Blumer, M.L., «Catalogue des peintures transportées d'Italie en France de 1796 à 1814», Bulletin de la Société d'Histoire de l'Art Français, 1936, 2ème fascicule ; Glück, «Les portraits équestres de Charles I para Van Dyck », Burlington Magazine, 1937, II, pp. 212-217 ; Michel (ed), La Peinture au Musée du Louvre, t. II. Écoles Étrangères. École flamande au XVIIème siècle, Londres-ParísNueva York, 1939, p. 87; pl. 94 ; Bouchot-Saupique, J., La peinture flamande du XVIIe siècle au Musée du Louvre, 1947, ed du Cercle d'Art, Bruselas, p. 69 ; Meyer, D., «Les Tableaux de Saint-Cloud sous Napoléon 1 ${ }^{\mathrm{er}}$ », Archives de l'Art français, 1969, vol 24, pp. 243 ; Wescher, P., Kunstraub unter Napoleon, Berlín, 1976, pp. 75, 140; Oldenburg, R., « Die Flamische malerei der XVII », Jahrbuch 1978, p. 75; Brejon de laVergnée, A. \& Foucart, J. \& Reynaud, N., Catalogue sommaire illustré des peintures du Musée du Louvre. I. Écoles flamande et hollandaise, París, 1979, I, p. 52 ; Larsen, E., L'Opera completa di Van Dyck, Milán, 1980, II, p. 111, nº 787 ; Brown, C., Van Dyck, Oxford, 1982, pp. 104-105 ; Larsen, E., Van Dyck. The Paintings, 1988, II, p. 326, n 829, vol I, p. 337, ill. 358 ; Laclotte \& Cuzin 1996, I, pp. 641-643 ; Gachenot, S., Les restaurations en peinture de Feréol de Bonnemaison, Maîtrise d'Histoire de l'Art à Paris IV, sous la direction d'Alain Mérot et Daniella Gallo, septembre, 2001, t. 3, no 55 ; Barnes, S. \& Pooter, N. \& Millar, O. \& Vey, H., Van Dyck. A Complete Catalogue of the Paintings, Yale, New Haven- Londres, 2004, p. 302, n III.68.

2 Roma, Palazzo Braschi, 1798; París, 1799, Louvre, exp. 1799, no $256 ; 1802, n^{\circ} 84 ; 1803, n^{\circ} 75 ; 1804, n^{\circ} 997$; Musée Napoléon ( $\mathrm{n}^{\circ}$ 257); Musée du Louvre ( $\mathrm{n}^{\circ}$ 1971) [Blumer, M.L., " Catalogue des peintures transportées d'Italie en France de 1796 à 1814 », Bulletin de la Société d'Histoire de l'Art français, 1936, 2ème fascicule]. El 15 de febrero de 1798 el ejército francés tomó el palacio Braschi en Nemi, acto al que siguió una revuelta delante del palacio, refugiándose el duque en Toscana, y después en Venecia, protegido por su tío, el Papa Pío VI. Sus bienes fueron confiscados, y en febrero de 1798, llevados por los franceses [véase A. González Palacios "A propos du surtout Braschi”, En Les dossiers du Musée du Louvre, Réunion des Musées Nationaux, 46 Exposition-dossier, p. 132]. Braschi poseía una importante colección de pinturas y esculturas, dispersa tras la revolución francesa, y vendida al rey de Baviera [veáse C. Pietrangeli, "Le collezioni private romane attraverso i tempi", Quaderno de circolo della caccia -2. Conversazione tenuta dal professore Carlo Pietrangeli il 21 febraio 1985), Roma 1985, pp. 15-16]. 
en estas páginas de seguir su rastro y justificar, en la medida de lo posible, el origen del Retrato ecuestre de Francisco de Moncada del Museo del Louvre, así como el de otras dos versiones conocidas en nuestro país, y conservadas en el Museo San Pío V de Valencia, y en la colección de la Casa de Alba [Figs. 2 y 3].

Van Dyck dotó al general español de la más impactante imagen imaginable en un retrato ecuestre, trasmitiendo no sólo su realidad fisonómica sino también su talante conciliador y pacifista. En un paisaje y a los pies de un árbol, Don Francisco de Moncada mira de frente, lleva armadura completa y un cuello blanco y plano que cae sobre los hombros; apoya la mano derecha en el bastón de mando, quedando oculta la izquierda, con la que sujeta las bridas del caballo. Como es típico en el atuendo de los capitanes españoles, el brazo izquierdo está ceñido por la banda roja, que ondea suavemente en el aire al tiempo que el caballo, de un blanco plateado y con abundantes crines, avanza al trote.

Don Francisco de Moncada nació en Valencia, el 28 de diciembre de 1586. Era hijo primogénito de Gastón de Moncada y Gralla, segundo Marqués de Aytona, y de Doña Catalina, Baronesa de Callosa y Taverna. Su padre, muerto en 1626, había sido Virrey de Cerdeña y Aragón, además de embajador de Felipe III en Roma. Don Francisco entró a servir en la armada española en 1621 y, en 1624, Felipe IV lo nombró embajador en la Corte Imperial en Viena, donde se ganó la estima de Fernando II. Asistió en 1627 a las fiestas de la coronación de Fernando III, rey de Bohemia, y en 1629 fue enviado a Bruselas junto a la Archiduquesa Isabel Clara Eugenia, sustituyendo al Cardenal de la $\mathrm{Cueva}^{3}$. Sus funciones en Flandes incluían la ayuda a la Archiduquesa en sus consejos y el control político de los españoles civiles y militares en los Países Bajos. Debía mantener informado al rey y a sus ministros de la situación de los negocios y gestionar el dinero enviado a la Península. Tuvo gran amistad con Rubens, que le sirvió de consejero en las negociaciones con Francia 4 .

Hombre de letras ${ }^{5}$, prudente, moderado y sorprendentemente tolerante, comprendió los errores que habían cometido sus predecesores 6 y se mostró partidario de conceder al pueblo flamenco una mayor participación en su propia administración, al ser consciente de que sólo acordándoles esa confianza permanecerían fieles al Imperio español: "No hay otro medio ni forma de encaminar las cosas del servicio de Su Magd. -escribe a Felipe IV el 5 de diciembre de 1629_ que confiar a los del país la pública salud de su patria y de su religión... Yo no sé, señor, como podemos conservar estas provincias en la devoción de S.M. desconfiando dellos, y no dándoles parte en el gobierno; y quando S.M. tuviera un exército grande y muy asistido de España juzgara yo por cosa peligrosa el tratar mal y despreciar esta gente, teniendo a Francia, Holanda y Inglaterra que les aconsejan que nos hechen y les ofrecen la asistencia para ello; y puedo asegurar a V. E. que no conozco a ninguno de quien no me parezca que se pueda hazer tanta confianza como de

\footnotetext{
3 Véase Gachard, M., Histoire politique et diplomatique de Pierre Paul Rubens, Bruselas, 1877, pp. 206-207.

${ }^{4}$ Véanse las cartas de Francisco Moncada a Felipe IV [Gachard, Op. Cit. 1877, pp. 206-213; 223-224; 319-324; Rooses, M. \&-Ruelens, Ch., Correspondance de Rubens et Documents épistolaires concernant sa vie et ses oeuvres, Amberes, 1887-1909, vol. V, pp. 396-400]. Sobre el encuentro de Moncada con María de Medicis en los Países Bajos [Henrard, P., Marie de Medicis dans les Pays-Bas, Bruselas, 1876, p. 77-83].

5 En 1623 escribió la Expedición de los catalanes contra griegos y turcos [primera ed. publicada en Barcelona, 1623; reimpreso en Madrid, 1775 y 1805; y en Barcelona, 1842; incluido en M. Ochoa, Tesoro de los historiadores españoles, París, 1841], donde se plantea la cuestión de la culpabilidad moral de los mercenarios y el grado de "institucionalización" de sus actuaciones. Su Vida de Manlio Torquato Severino Boecio, fue publicada en Francfort después de su muerte, en 1642, y también fue autor de la Antigüedad del Santuario de Montserrat.

6 Waddington dice así de él: « Activo, inteligente, conocedor de los Países Bajos donde había servido bajo las órdenes de Spínola, comprendía que para calmar los espíritus era necesario romper con la política absolutista de hispanismo de su predecesor" [Waddington, A., La République des Provinces Unies, la France et les Pays-Bas Espagnols de 1630 à 1650, 1895-1897, vol I, p. 103]
}

AEA, LXXIX, 315, JULIO-SEPTIEMBRE, 307-332, 2006, ISSN: 0004-0428 
cualquiera de nosotros"7. En vano propuso transferir la administración general de los asuntos flamencos a la ciudad de Bruselas. En 1630 fue nombrado Comandante Jefe de la Marina y, tras la muerte de la Archiduquesa, ocupó el cargo de Gobernador de los Países Bajos hasta la llegada del Cardenal-Infante Don Fernando de Austria. La liberación de Breda (1625) fue uno de sus mayores triunfos militares, y la ciudad hizo batir monedas en su honor. En 1635 acompañó al Cardenal-Infante en su expedición al Condado de Clèves, donde murió repentinamente a causa de unas fiebres en el campo de Goch.

Es bien conocido que el modelo del retrato ecuestre está basado en prototipos que remontan a la Antigüedad, como la famosa estatua de Marco Aurelio o el Balbo del Museo napolitano de Capodimonte $^{8}$. Según Bellori ${ }^{9}$, Van Dyck se inspiraría en el Retrato ecuestre de Carlos V de Tiziano del Museo del Prado, sin duda el prototipo más conocido; pero los modelos más cercanos, tanto para Van Dyck como para el retratado, serían los de Rubens, claro está, también inspirado en Tiziano. La composición se inspira del Retrato ecuestre del Duque de Lerma que Rubens realizó en su primera visita a España (1603) y que hoy conserva el Museo del Prado ${ }^{10}$, donde el mismo caballo blanco trota de frente al espectador. Rubens tomó el detalle del San Martín de El Greco, utilizándolo de nuevo para el Retrato ecuestre del Cadenal-Infante del Museo del Prado (1635) ${ }^{11}$. Posiblemente Van Dyck conocía la composición por dibujos del maestro ${ }^{12}$, pues es notoria su vinculación; no sólo en lo que se refiere a la posición del modelo y su caballo, sino también a la ubicación del árbol a su derecha. Van Dyck prescinde de las alusiones bélicas que ocupan el fondo del cuadro de Rubens, y concentra la atención en el jinete y su caballo, trasformando la escena en un plácido trotar por una hermosa pradera. No estamos frente a una marcha guerrera, sino ante un paseo sosegado, sin la nota inquietante de la guerra, lo que coincide muy bien con el sentimiento pacifista del retratado. En este retrato se hace patente, una vez más, el poder de penetración psicológica del pintor que, a pesar del aspecto marcial de la fórmula ecuestre, supo captar en el rostro del general su humanidad, complaciéndose a la vez en la belleza de la Naturaleza, lo que coincide muy bien con el gusto inglés por el paisaje. De hecho Van Dyck es un excelente pintor de paisajes, que podría haber competido con cualquier especialista del género ${ }^{13}$.

Igual que Rubens, Van Dyck cultivó las diferentes modalidades de retrato ecuestre. Utilizó la fórmula del caballo en escorzo avanzando hacia el fondo y el jinete vuelto hacia el espectador en

\footnotetext{
7 Gachard, P., "Don Francisco de Moncada, Marqués de Aytona”, Biographie Nationale de l'Académie Royale des Sciences, des Lettres et des Beaux-Arts de Belgique, I, Bruselas, 1866, p. 579. No hemos tenido acceso a la tesis doctoral de Veimer, R., Spanje en de Zuiderlijke Nederlanden tijdens de landvoogdij van Isabella, Aytona en de kardinalInfant, 1629-1641, Gante, 1998.

8 A propósito de éstas y otras fuentes de inspiración, Véase Strong, R., Charles I on horseback, Londres, 1972.

${ }_{9}^{9}$ Bellori menciona que el Retrato ecuestre de Carlos I en la National Gallery de Londres fue concebido por Van Dyck "ad imitazione di Carlo Quinto espresso da Tiziano" [Bellori, G.P., Le vite de' pittori, scultori ed architetti moderni, Roma, 1672, p. 260].

${ }^{10}$ Lienzo, 283 x 200 cm. Madrid, Museo del Prado [nº 3137]. Véase Díaz Padrón, M., \& Padrón Mérida, A., El siglo de Rubens en el Museo del Prado. Catálogo razonado de la Pintura Flamenca del siglo XVII, Madrid, 1995, Vol. II, pp. 1064-1068.

11 Véase Díaz Padrón \& Padrón Mérida, Op. Cit. 1995, II, pp. 974-978, nº 1687.

12 Se conocen dos dibujos preparatorios vinculados al Retrato del duque de Lerma de Rubens, en el Museo del Louvre [Inv: 20185; Véase Lugt, F., Répertoire des dessins du Musée du Louvre. Ecole Flamande, II, 1949, nº 1018; Burchard, L. \& D'Hulst, R.A., Rubens Drawings, Corpus Rubenianum Ludwig Burchard, I-II, Bruselas, 1963, n 30] y en la antigua colección del duque de Weimar [Véase Glück J.A. \& Haberditzl, F.M., Die Handzeichnungen von Peter Paul Rubens, Berlín, 1928, n 47].

13 A propósito de la actividad de Van Dyck como paisajista véase Hind, M., "Van Dyck and English Landscape", Burlington Magazine, dic. 1927, pp. 292-297 ; Jaffé, M., "A landscape by Rubens, and another by Van Dyck", Burlington Magazine, 1966, pp. 410-416 ; Royalton-Kisch, M., La Lumière Naturelle. Dessins et aquarelles de paysage de Van Dyck et ses contemporains, Cat. Exp. Amberes, Rubenshuis, 1999.
} 


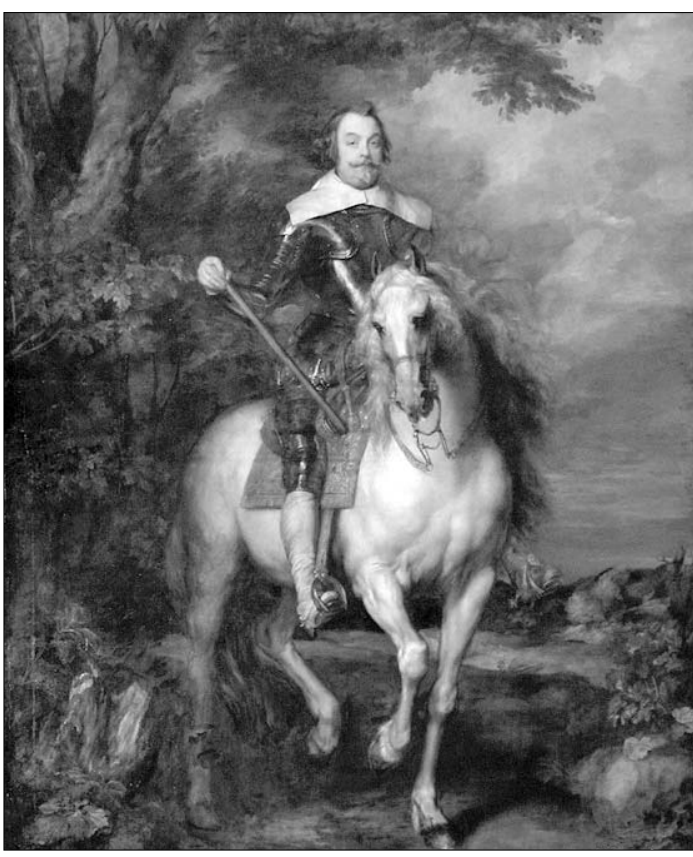

Figura 1. Anton van Dyck. Retrato de Francisco de Moncada, marqués de Aytona. París, Musée du Louvre.

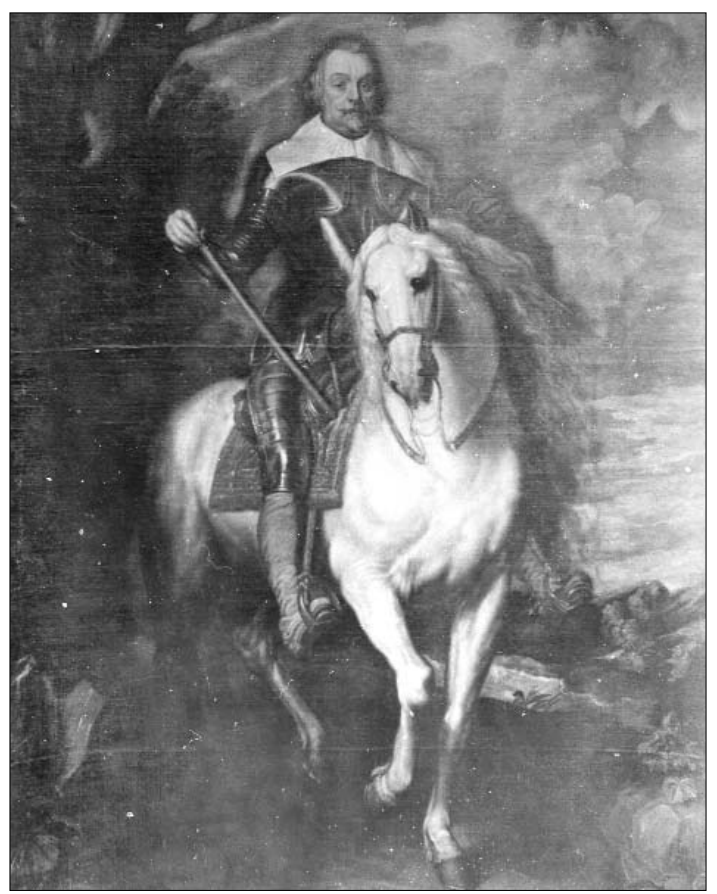

Figura 3. Según A. van Dyck. Retrato de Francisco de Moncada, marqués de Aytona. Madrid, Palacio de Liria, Colección de la duquesa de Alba.

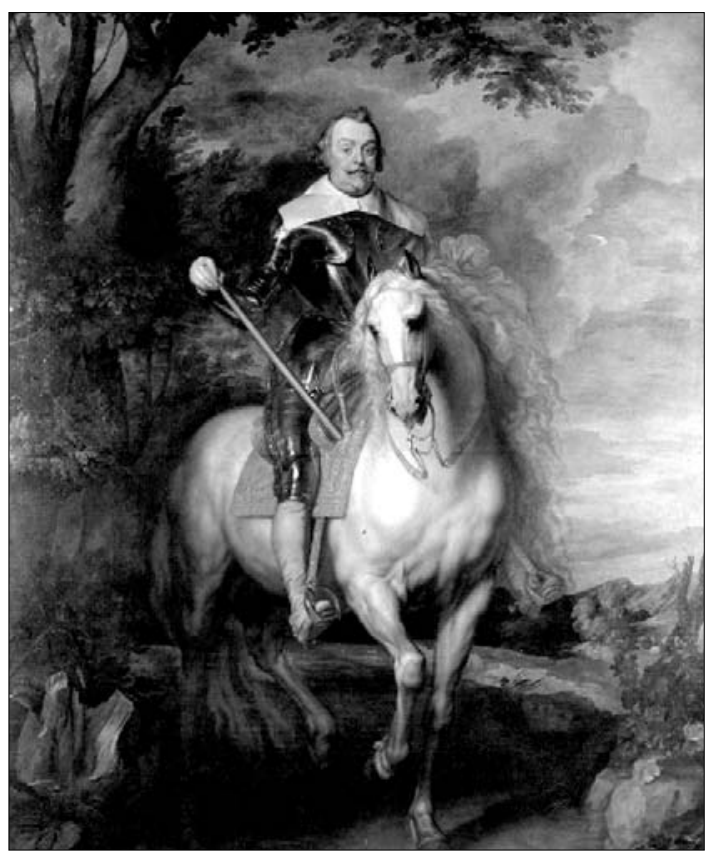

Figura 2. Anton van Dyck. Retrato de Francisco de Moncada, marqués de Aytona. Valencia, Museo San Pío V.

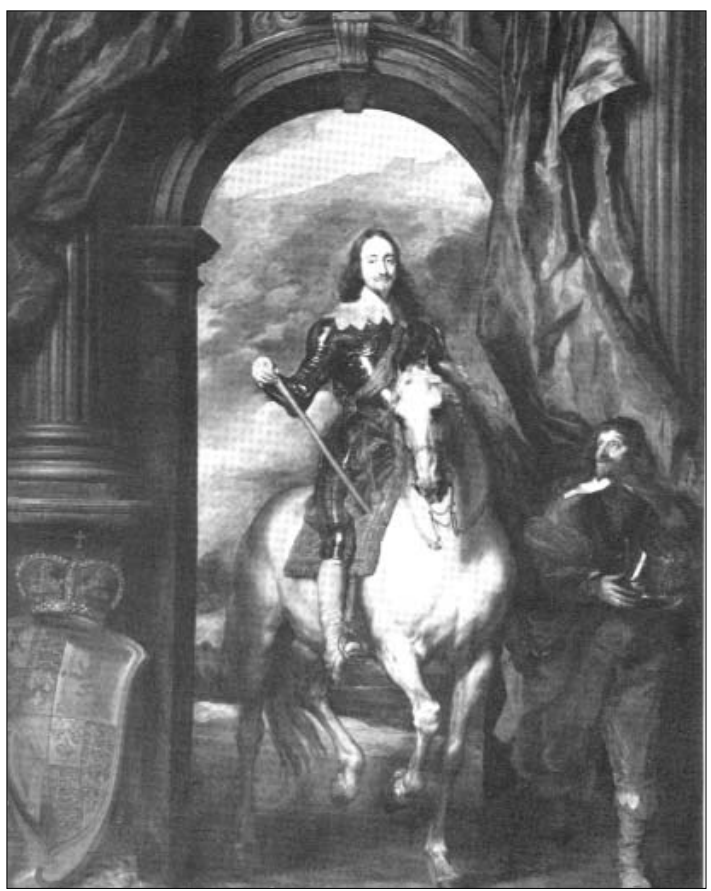

Figura 4. A. van Dyck. Retrato de Carlos I de Inglaterra con Monsieur Antoine. Windsor Castle

AEA, LXXIX, 315, JULIO-SEPTIEMBRE, 307-332, 2006, ISSN: 0004-0428 
el retrato de Giovanni Paolo Balbi ${ }^{14}$ (hacia 1627), y el del Marqués Anton Giulio Brignole Sale ${ }^{15}$, en que repite el mismo esquema frontal. Cuando llegó a Bruselas en 1634, al tiempo que ejecuta el retrato de Moncada que estudiamos, realiza también el Retrato ecuestre del príncipe Thomas Francis de Saboya, hoy en la Galería Sabauda de Turín ${ }^{16}$, para el que eligió una postura de costado y en corveta, aunque con el mismo efecto. Vemos pues que Van Dyck alterna ambas composiciones simultáneamente.

Retomando a Rubens, Van Dyck elige para el Retrato de Francisco de Moncada la fórmula más osada y difícil, repitiendo el esquema de los retratos de Cornelius de Wael y de Carlos I de Inglaterra y Monsieur de Saint Antoine [Fig. 4] ${ }^{17}$ que había ejecutado en Londres poco antes, en 1633. Idéntica fórmula, aunque invertida, utilizó Van Dyck para un Retrato de Felipe IV del que no se encuentra rastro en la actualidad, pero que debió ejecutar a juzgar por la inscripción del grabado de Peter de Jode [Fig. 5] ${ }^{18}$. Van Dyck busca una estípite enormemente elegante, con el caballo y el jinete en un eje vertical, avanzando a rítmico compás de frente al espectador, quien lo ve desde abajo y se encuentra sobrecogido por tan imponente imagen. Al igual que Carlos I y Felipe IV, Moncada figura como comandante, con armadura y bastón de mando, montado en un caballo en idéntica posición. Van Dyck prescindió del gran arco de medio punto que enmarca la figura de ambos monarcas y de la nota de servilismo del escudero en el cuadro de Carlos I, optando por colocar al general español en un espacio natural arbolado, sin otros elementos que distraigan la atención. Van Dyck sigue de manera sublime esta fórmula que inició Rubens, con el añadido de la elegancia de eje vertical e imponente. Son pocos los pintores que lograron esta fórmula con acierto: aparte de Rubens y Van Dyck, lo hizo también Gaspar de Crayer; pero ni siquiera nuestro Velázquez se atrevió a la osadía de tal escorzo.

El British Museum de Londres conserva un dibujo con dos estudios de un caballo en la misma posición [Fig. 6] ${ }^{19}$, que el profesor Vey estimó preparatorios para el retrato de Moncada del Louvre ${ }^{20}$, pero también asociado al de Carlos I en Windsor Castle, cuyo dibujo definitivo es conocido en el museo británico ${ }^{21}$. Pensamos que los ensayos de Van Dyck fueron útiles para ambas composiciones, realizadas sucesivamente 22 .

Es posible fechar con precisión el retrato de Moncada, en el otoño de 1634, teniendo en cuenta que el general llegó a los Países Bajos en 1633, y que muere poco después de la llegada del Cardenal-Infante, en 1635. El Marqués de Aytona tenía entonces cuarenta y ocho años y su carrera estaba en pleno auge tras el triunfo en Breda. Aprovechó la corta estancia de Van Dyck en los Países

${ }^{14}$ Lienzo, 370 x $263 \mathrm{~cm}$ (medidas actuales); 266 x $198 \mathrm{~cm}$ (medidas originales). Parma, Fondazione Magnani Rocca [Véase Van Dyck a Génova. Grande pittura e collezionismo, cat exp. Génova Palazzo Ducale, 1997, n 62].

15 Lienzo, 282 x 198 cm. Génova, Galleria di Palazzo Rosso [Inv. PR 48; Véase Génova, cat exp. cit. 1997, nº 59].

${ }^{16}$ Lienzo, 315 x $236 \mathrm{~cm}$ [Véase Wheelock, in Anthony van Dyck, Cat. Exp., Washington D.C., National Gallery of Art, 1990-1991, nº 71, pp. 275-276]

17 A propósito de esta pintura, Véase Millar, O., En Van Dyck in England, Cat. Exp., Londres, National Portrait Gallery, 1982-1983, nº 11

18 Con la inscripción, abajo a la derecha: "Pet. Cocus auctor / Ant. Van Dÿck pinxit. Cum Privilegio. Pet de Iode Sculptor" [Vid. The New Hollstein Ducth \& Flemish Etchings Engravings and Woodcuts. 1450-1700. Anthony Van Dyck, Part VI, 2002, p. 139-140, n 492]. Existe retrato basado en esta composición, adscrito en el pasado a Van Dyck y su escuela, y hoy atribuido a P. Novelli, en la colección Odescalchi de Roma [Di Steffano, G., Pietro Novelli il Monrealese, Palermo, 1989, p. 225, nº 53; Cit. Boccardo, in, Bolletino dei Musei Genovesi, Anno X, n 28-29-30, EneroDiciembre 1998, p. 108, fig. 5].

${ }^{19}$ Carbón y tiza sobre papel azul, 429 x $366 \mathrm{~cm}$. Londres, British Museum, Department of Prints \& Drawings [Inv. No 1874.8.8.22]. Véase Vey, H., Die Zeichnungen Anton van Dyck, 2 vols., Bruselas,1962, nº 208.

20 Ibidem, I, p. 282.

21 Ibidem, pp. 280-281, n 207.

22 Vey, Op. Cit. 1962, I, pp. 281-282, nº 208, 209. 


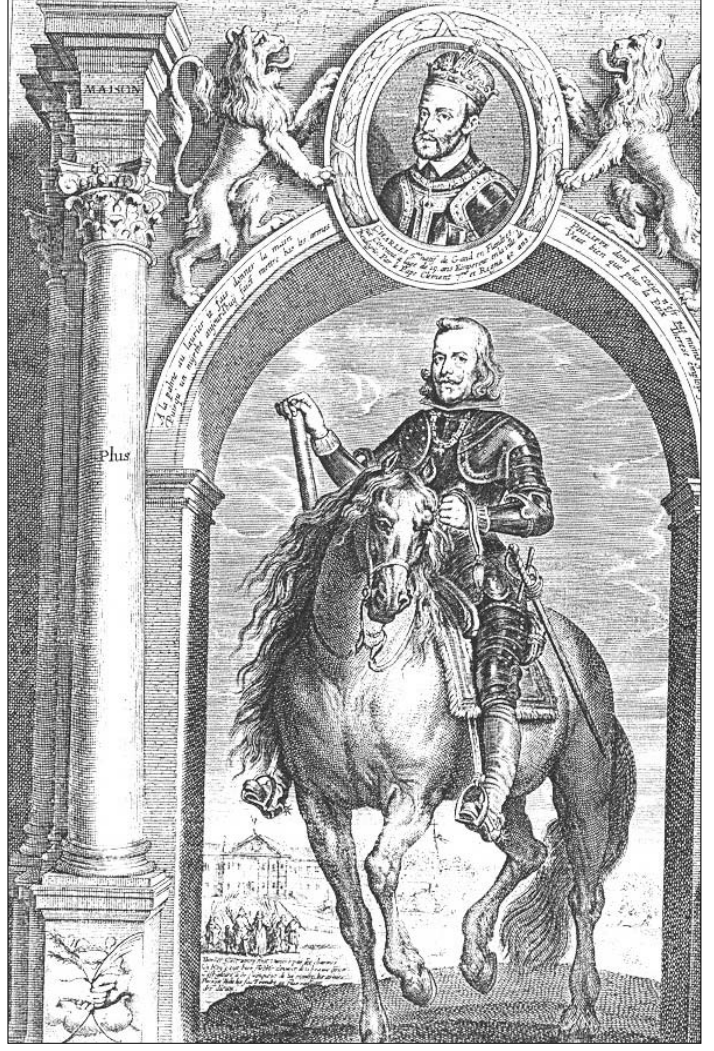

Figura 5. Peter de Jode según Van Dyck. Retrato de Felipe IV. Grabado.
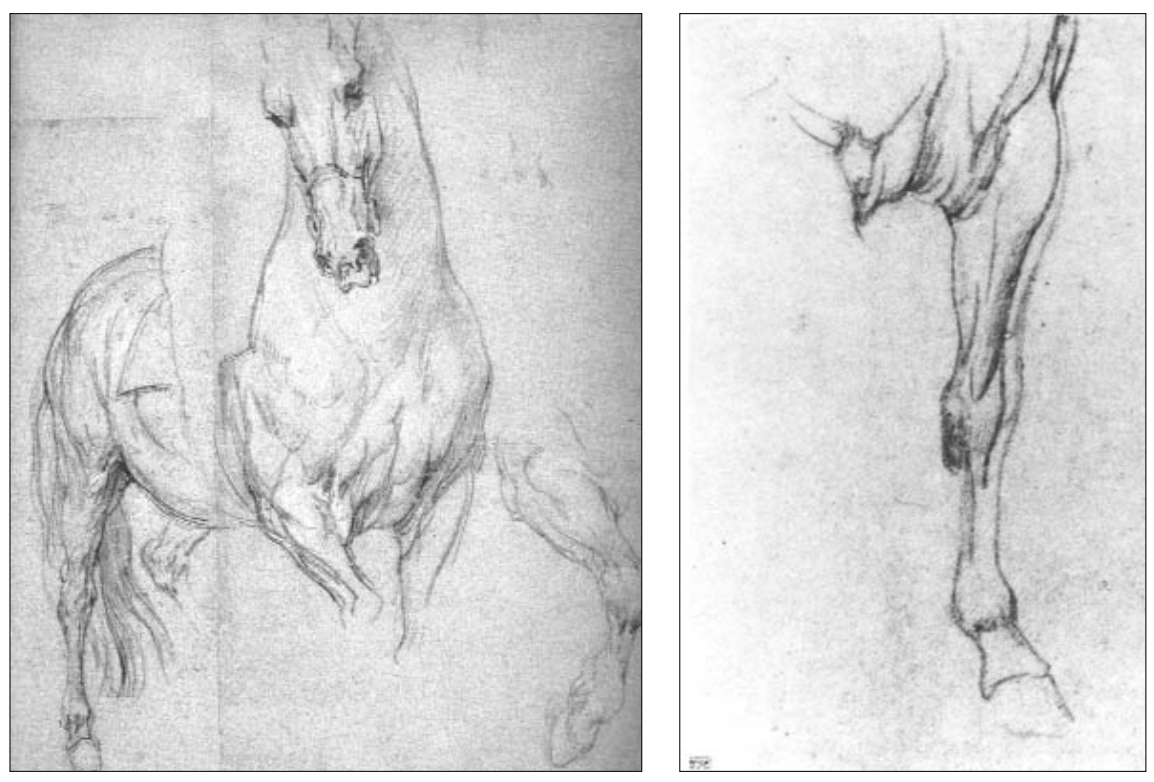

Figura 6. A. van Dyck. Estudios de caballo. (recto y verso). Londres, British Museum.

AEA, LXXIX, 315, JULIO-SEPTIEMBRE, 307-332, 2006, ISSN: 0004-0428 
Bajos para hacerse retratar a caballo, y Van Dyck se sirvió de la fórmula que recientemente había utilizado para Carlos I de Inglaterra. Quizá fuera decisión del mismo Aytona, que podría haber visto los dibujos para el recién terminado retrato del monarca inglés: una composición que Van Dyck estudia con detenimiento, a juzgar por los dibujos que han llegado a nosotros.

Pensamos que este retrato del Museo del Louvre, sin huellas en el pasado y de gran calidad como anotamos al inicio de este trabajo, llegó a parar a la colección de Don Gaspar Méndez de Haro, VII Marqués del Carpio, Duque de Montoro, Conde-Duque de Olivares y Marqués de Eliche, quien reunió una importante colección de pinturas ${ }^{23}$. Así, es posible que se trate de la siguiente pintura inventariada en 1651 en su colección: " $n^{\circ}$ 178. -una pintura en lienço que es el Retrato del Marqués de Aytona en Vn cavallo blanco Armado La caveça descubierta con Balona Cayda La mano derecha sobre el bastón de General y en el braço yzquierdo Una banda colorada debajo de Unos arboles de mano de Valdique de cinco baras de Cayda y poco más o menos de quatro de ancho con su marco negro" 24 . La descripción es del todo coincidente con el retrato del Louvre en cuestión, y las medidas, trascritas de varas a centímetros, son superiores a las actuales (corresponderían a unos 420 x $330 \mathrm{~cm}$, frente a los 307 x $242 \mathrm{~cm}$ que ostenta en la actualidad).

En el inventario siguiente del citado marqués, que recoge sus posesiones en Madrid en 1689, figura de nuevo esta pieza, en su Palacio del Jardín de San Joaquín, ubicada en la escalera: " $n^{\circ}$ 247. -Un Rettratto del Marqués de Aytona en Un Cavallo blanco Armado Con El bastton en la mano en Un país con Un Arbol grande y un tronco original de Antonio Vandique de quattro varas de Cayda y tres Varas y sesma de ancho Con marco negro En Cincuentta y Cinco mill Rs. 55.000"25. Las

23 Don Gaspar había nacido en Madrid en 1629. Estuvo en las dependencias del príncipe Baltasar Carlos de Zaragoza en 1645 y, en 1648, fue nombrado Gentilhombre de Cámara al servicio de Felipe IV, recibiendo sucesivamente los cargos de Montero Mayor, Alcalde del Buen Retiro, de El Pardo, de la Zarzuela, de Valsaín y de los Alcázares de Córdoba y Sevilla. Era sobrino del Conde-Duque de Olivares y del Conde de Monterrey, ambos muertos sin descendencia, por lo que heredó una importante herencia. Casó con 21 años con la hija del duque de Medinaceli, Antonia María de la Cerda. Muerta ésta en 1671, contrajo matrimonio con Teresa Enríquez. La única hija de ambos, Catalina, nació en 1672. Según el primer inventario conocido de su colección, realizado en 1651 cuando apenas tenía 22 años, poseía más de 300 pinturas, entre ellas, la famosa Venus del Espejo de Velázquez [Véase Pita Andrade, J. M., "Los cuadros de Velázquez que poseyó el séptimo Marqués del Carpio", Archivo Español de Arte, 1952, pp. 226-232; Harris, E., "El Marqués del Carpio y sus cuadros de Velázquez", Archivo Español de Arte, 25, 1952, pp. 223-236]. En 1660 adquirió una finca en la Moncloa, en cuya decoración trabajaron los fresquistas Mitelli y Colonna, residencia que decoró con fasto. Palomino nos informa de que encargó copias de algunas de sus pinturas más famosas tras la adquisición de la finca de la Moncloa en 1661: "Copiáronse en las paredes los mejores cuadros, que se pudieron haber, con mucha puntualidad. Hay de Rafael, de Tiziano, de Veronés, de Van Dick, de Rubens, de Velázquez, y de otros muchos, con marcos de oro, también pintados, y colgaduras de telas fingidas famosísimamente" [Palomino, A. Museo Pictórico y Escala Óptica. Vol. III: El Parnaso Español pintoresco laureado. Madrid, 1947 (1724), pp. 925-926]. Tras el atentado frustrado contra el rey en 1662, fue objeto de sospechas y se le apartó de la Corte. Participó en la guerra de Portugal, quedando preso cuatro años. Llegó como embajador a Roma en 1675, llevando consigo algunas piezas de su colección. En Italia se empeñó en la adquisición de obras de arte, fundamentalmente de pintura veneciana, desprendiéndose para ello de algunas pinturas. Murió en Nápoles en 1687 [véase Ghelli, M. E., "Il Viceré marchese del Carpio (1683-1687)", Archivo storico per le provincia napolitane, 1933, pp. 280-318; 1934, pp. 257-282]. Sobre la figura del Marqués como coleccionista Véase Haskell, F., Patron and Painters. Art and Society in Baroque Italy (1963), New Heaven-Londres, 2001, pp. 190-192; Andrés, G., El Marqués de Liche: bibliófilo y coleccionista de arte, Madrid, 1975; López Torrijos, R., "Coleccionismo en la época de Velázquez: el Marqués de Heliche”, en Velázquez y el arte de su tiempo, V Jornadas de Arte, Madrid, 1990, pp. 27. 36; Burke \& Cherry, Op. Cit. 1997, pp. 153-170; 437-453; 462-483; 726-786; Caccioti, B., "La collezione del XVII Marchese del Carpio tra Roma e Madrid", Bolletino d'Arte, 1994, pp. 133-196; Marías, F., "Don Gaspar de Haro, Marqués del Carpio, coleccionista de dibujos", in Arte y diplomacia de la Monarquía Hispánica del siglo XVII, Madrid, 2003, pp. 209-219; Checa Cemades, F., "El Marqués del Carpio (1629-1687) y la pintura veneciana del Renacimiento. Negociaciones de Antonio Saber", Anales de Historia del Arte, 2004, 14, pp. 193-212].

24 Burke \& Cherry, Op. Cit. 1997, pp. 437-474, no 178.

25 Burke \& Cherry, Op. Cit. 1997, p. 843, nº 235. 
medidas corresponderían a 340 x $270 \mathrm{~cm}$ aproximadamente y, si bien es sabido el carácter aproximado de las mediciones en varas de tantos inventarios de la época, pensamos que la pintura debió reducirse para adaptarse a su ubicación en la escalera del Palacio. El inventario y la tasación de 1689 corren a cargo de Claudio Coello, pintor de Cámara del Rey, y José Donoso, también pintor. Burke y Cherry, en su trabajo sobre los inventarios españoles del siglo XVII ${ }^{26}$, identificaron esta pintura con la copia de la colección Alba, de la que trataremos a continuación, sin percatarse quizá de su alta tasación. Al recorrer este inventario del Marqués del Carpio, comprobamos que se trata del Van Dyck más caro de la colección ${ }^{27}$, cuyo valor sobrepasa lo estimado para otros cuadros originales, como Las Meninas, que se tasan a 4.000, y el Jardín del Amor de Rubens, que iguala la tasación en 55.000 reales $^{28}$. Esta tasación, prueba de la alta estima del retrato, sólo puede corresponder a una pieza excepcional, y no concuerda con la copia de la colección de Alba, pero sí con un retrato de insuperable valor y calidad como el del Museo del Louvre.

La copia de la colección Alba estuvo en la colección de la madre de Don Gaspar, como especificaremos más abajo. No debe extrañar que varios ejemplares del mismo retrato quedaran en la misma familia, pues el encargo de retratos "a pares" era práctica habitual. No sabemos por qué vía llegó el lienzo del Louvre a la colección Braschi de Roma, donde estuvo hasta 1798, que es su procedencia más antigua conocida ${ }^{29}$; pero podría relacionarse con la estancia de Don Gaspar en Roma, como embajador de Carlos II, desde marzo de 1676, y con su muerte en Palermo en 1687. Es conocido que llevó parte de sus posesiones a Italia, y que se desprendió de algunas pinturas para adquirir otras. Al no tener noticia anterior a 1798 del original del Louvre, podría pensase que el retrato quedara allí. No obstante es posible que pasara a propiedad de sus herederos y que fuera después adquirido por coleccionistas extranjeros, como fue frecuente en aquellos años, que vieron la dispersión por toda Europa de las pinturas de esta prodigiosa colección.

Hemos apuntado líneas atrás la hipótesis de una primera reducción del cuadro en vías de su ubicación, y pensamos que otras tuvieron lugar posteriormente. La pintura fue sometida a sucesivas restauraciones, algunas de ellas poco afortunadas, realizadas tanto en Roma, donde se dice tenía numerosos repintes que cubrían el rostro restándole nobleza ${ }^{30}$, como en París, donde fue confiado primeramente a Hacquin, que sentó la capa pictórica afectada por ampollas. En 1818 Bonnemaison procedió al reentelado y a la substitución del bastidor original ${ }^{31}$. Otra restauración tuvo lugar en 1855, en la que se eliminaron antiguos repintes y se reconstituyó parte del rostro,

26 Burke \& Cherry, Op. Cit. 1997, p. 876, nota 21.

${ }^{27}$ Los retratos originales de Van Dyck se tasan entre 1.100 y 11.000 reales. El precio más común para los retratos ronda los 3.000 reales. Un retrato de Felipe I a caballo, copia de Van Dyck, se tasa en 3.000, y un Retrato ecuestre del Cardenal Infante, original, en 33.000 .

28 Sólo sobrepasan esta tasación los Correggio ( $\mathrm{N}^{\circ}$ 1101, Un Mercurio, a 420.000 reales y otras dos pinturas a 120.000) y los Caracci ( $\mathrm{n}^{\circ} 180$, Cristo muerto, a 60.000). Los Tintoretto más altos rondan los 11.000 o 16.500, a lo sumo. Sólo el Jardín del Amor de Rubens ( $\mathrm{n}^{\circ}$ 434) iguala la tasación de 55.000 reales.

${ }^{29} \mathrm{El} 15$ de febrero de 1798 el ejército francés tomó el palacio Braschi en Nemi, acto al que siguió una revuelta delante del palacio de Braschi en Roma, refugiándose el duque en Toscana, y después en Venecia, protegido por su tío, el Papa Pío VI. Sus bienes fueron confiscados, y en febrero de 1798, llevados por los franceses [véase González Palacios, A., "A propos du surtout Braschi”, in Les dossiers du Musée du Louvre, Réunion des Musées Nationaux, 46 Exposition-dossier, p. 132]. Braschi poseía una importante colección de pinturas y esculturas, dispersa tras la revolución francesa, y vendida al rey de Baviera [véase Pietrangeli, C., "Le collezioni private romane attraverso i tempi", Quaderno de circolo della caccia -2. Conversazione tenuta dal professore Carlo Pietrangeli il 21 febraio 1985), Roma 1985, pp. 15-16]

30 'Il est de regretter que la tête de l'homme ait souffert des restaurations maladroites, qu'elle a éprouvée lorsque ce tableau était dans la galerie du Prince Braschi. (...) on enlevera les lourds repeints qui couvrent cette figure et la deshonorent" [Lavallée, 1804-1815, IV, p. 6].

${ }^{31}$ Gachenot, Op. Cit. 2001, No 55.

AEA, LXXIX, 315, JULIO-SEPTIEMBRE, 307-332, 2006, ISSN: 0004-0428 


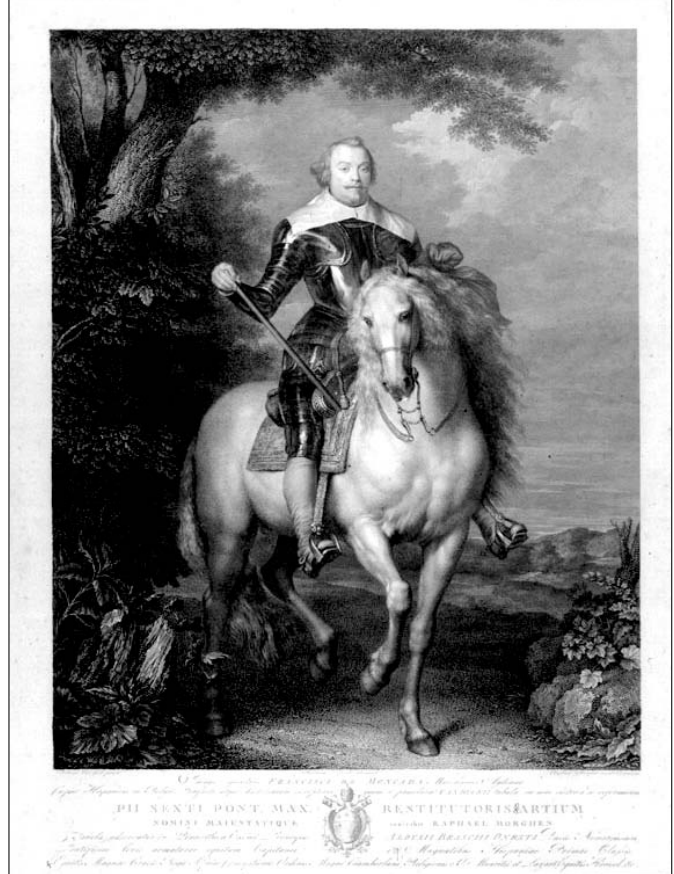

Figura 7. R. Morghen según A. van Dyck. Retrato de Francisco de Moncada, marqués de Aytona. Grabado.

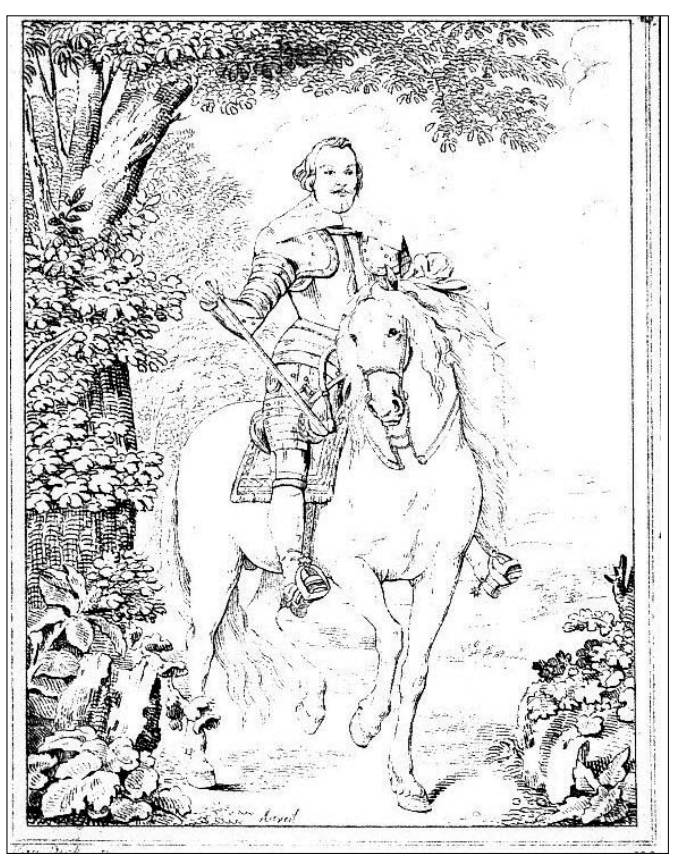

Figura 9. A. Réveil según Van Dyck. Retrato de Francisco de Moncada, marqués de Aytona. Grabado.

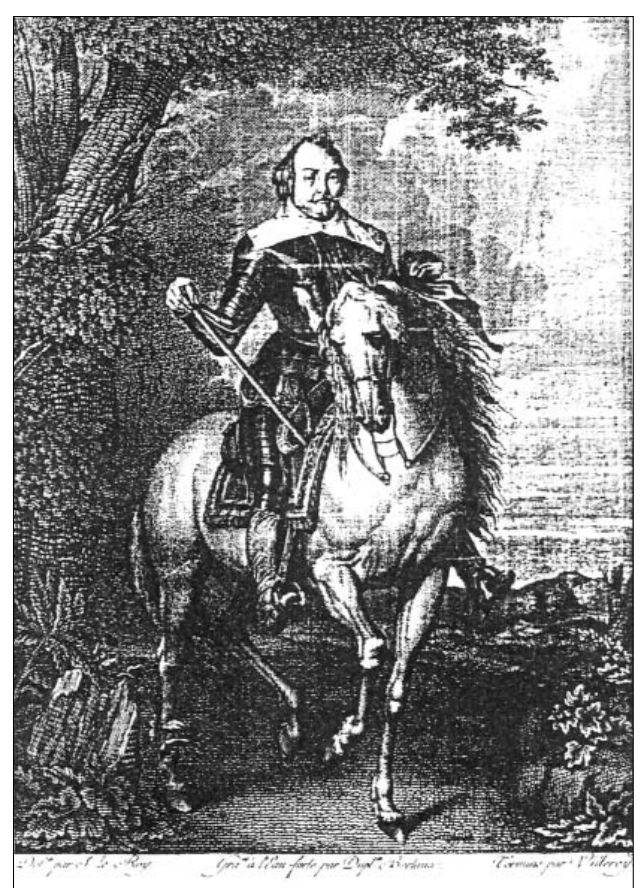

Figura 8. J. Dupleiss-Bertaud y Villerey según A. van Dyck. Retrato de Francisco de

Moncada, marqués de Aytona. Grabado.

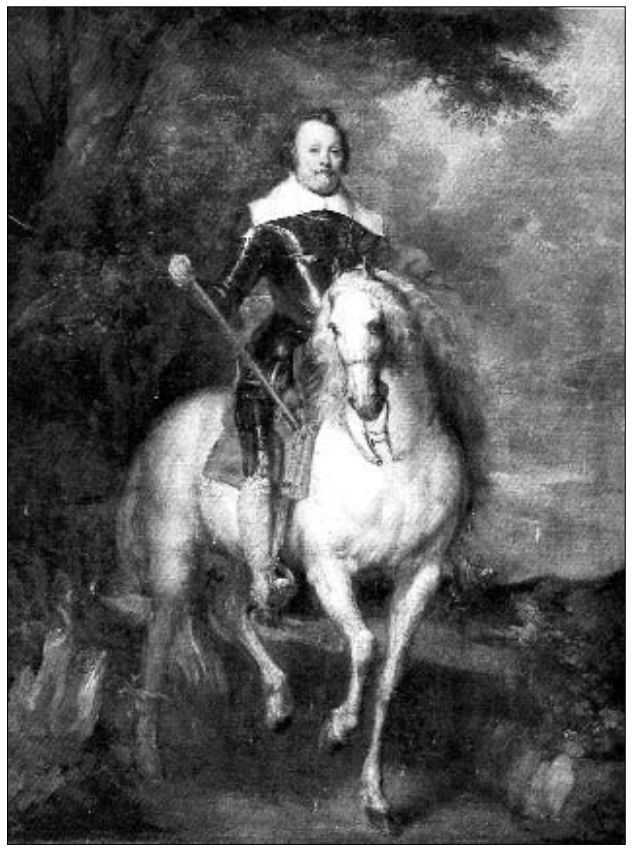

Figura 10. Según A. van Dyck. Retrato de Francisco de Moncada, marqués de Aytona. Paradero desconocido. 
del paisaje y de la grupa del animal ${ }^{32}$. De hecho, la observación directa del lienzo permite ver que ha sufrido las alteraciones propias del paso del tiempo y de estas intervenciones.

El grabado de Rafaello Morghen [Fig. 7] ${ }^{33}$, fechado en 1793 cuando la pintura se encontraba en posesión del príncipe Braschi en Roma, es fundamental para demostrar el mayor tamaño del lienzo por entonces. Tenía más espacio en la parte superior, con mayor despliegue del follaje de los árboles. Esto apunta a la reducción del lienzo en alguna intervención. Esto es fácil de constatar cuando lo comparamos con el grabado realizado por Jean Duplessis-Berteaux y Villerrey cuando el lienzo ingresa en el Museo Napoléon [Fig. 8] ${ }^{34}$. Otro grabado fue realizado por A. Reveil en el siglo XIX [Fig. 9].

Hay otras razones para creer que el espacio concebido por Van Dyck era más holgado, por comparación con otros retratos suyos de la misma modalidad, como el del Príncipe Thomas Francis de Saboya, realizado en la misma fecha, cuyo esquema compositivo reserva mayor espacio circundante al jinete. Estas sucesivas intervenciones justificarían la diferencia de medidas en los sucesivos inventarios donde se registra la pintura.

El ejemplar de la Casa de Alba, de menores dimensiones [Fig. 3. Lienzo, 248 x 210] ${ }^{35}$ es repetición de inferior calidad. El catálogo de la colección de los duques, realizado por Barcia a principios del siglo XX, registra la pintura: " $\mathrm{n}^{\circ}$ 183. -Retrato ecuestre de D. Francisco de Moncada, III, Marqués de Aytona. An. 210. Alt, 2,48", considerándola una copia antigua donde pudiera haber algo de mano de Van Dyck ${ }^{36}$. El duque de Berwick y Alba nos informa, en uno de los discursos de la Real Academia de Bellas Artes, de su procedencia en la colección de Doña Catalina Fernández de Córdoba y Aragón, Marquesa del Carpio y madre de Don Gaspar, según

32 Así nos cuenta Viel Castel su visita al taller del restaurador Godefroy, ocupado en el retrato de Moncada, el 20 de junio de 1855: « Je me suis Donc transporté dans l'atelier du restaurateur émérite que j'ai trouvé armé d'un palette lourdement chargé devant le portrait équestre de François de Moncade, marquis d'Aytona, peint par Van Dyck. Monsieur Villot dit dans son catalogue : «cette peinture passe pour le plus beau portrait de Van Dyck». Cela dit, voyons comment Godefroy en entend la restauration, je vais rapporter son discours : «Vous avez peine, Monsieur le comte, a reconnaître ce portrait ! Il est bien changé depyuis que je l'ai déverni... Les peintres qui avaient commencé des copies les recommenceront. (ici Godefroy se livre à une hilarité contenue). La tête de Moncade s'enlevait en vigueur sur un nuege claire, elle se détache actuellement en clair sur un nuage vigoureux !... il se trouvait un tronc d'arbre sur le premier plan, il n'y a plus qu'une pierre !... le train derriére le cheval est perdu, le contour a disparu, mais M. Villot doit m'apporter une ancienne gravure de cette oeuvre et je referai le train de derrière » (ici Godefroy se rengorge). Je trouve le ton général de ce portrait actuellement bien froid », repondis-je. Godefroy prit une bouteille dans laquelle croupissait une sorte de boue noirâtre. "Voici mon remède, avec un peu de cette sauce je redorerai le Van Dyck. Quand je dévernis un tableau, je garde la pourssière du vieux vernis, j'y ajoute de l'esprit de vin, et voilà ma sauce à refaire les vieux tableaux ». Après cette belle karangue Godefroy reprit ses pinceaux pour refaire un ciel dans je sais plus quel paysage » [Mémoires du comte Horace de Viel-Castel sur le règne de Napoléon III, pp. 161-162].

33 Aguafuerte y buril, con la inscripción: "Ritratto di Francesco Moncada, marchese de Aytona / Romae, 1793". Raffaello Morghen (Nápoles, 1758-Florencia, 1833), de familia de grabadores, se trasladó a Roma donde trabajó en el taller de Giovanni Volpato, convirtiéndose en su principal colaborador. Según su biógrafo, Palmerini, es uno de los más bellos grabados que realizó, para cuya ejecución empleó diez meses, destacando en él el respeto a los pintores, la manera de tratar las carnaciones, inteligencia en el tratamiento de los paños, y gran gusto para el paisaje. Se expuso en Pitture, disegni e stampe del '700 dalle collezione dei Museo Civici di Storia ed Arte di Trieste, Museo Sartorio, Trieste, 28-06/31-12-1972.

${ }^{34}$ Lavallée, J., Galerie du Musée Napoléon, 1804-1815, t. IV, pl. 275.

35 Barcia, A. M., Catálogo de la Colección de pinturas del Exc. Duque de Berwick y De Alba, Madrid, 1911, pp. 165166, n 183; Berwick y Alba, Discursos leídos ante la Real Academia de Bellas Artes de San Fernando en la recepción pública del Ecxmo. Sr. Duque de Berwick y de Alba, individuo de número de la academia de la Historia y Honorario de la Española, celebrada el 25 de mayo de 1924, Madrid, 1924, p. 109; Díaz Padrón, La pintura flamenca del siglo XVII en España, 1976 (ms.), IV, fol. 1163; Burke, P., Private collections of italian art in sevententh century in Spain, 1984, II, p. 224.

36 Barcia, Op. Cit. 1911, pp. 165-166, n 183. Añade Barcia en nota: "Este cuadro ha sido estimado por algunos inteligentes como repetición del de París. Al menos es una excelente copia antigua en la que pudiera haber algo de mano de Van Dyck. Perteneció a D. Luis Méndez de Haro y Guzmán, Conde Duque de Olivares, y es uno de los 32 cuadros que vinieron de la Casa de Alba. Este retrato fue grabado por Morghem; la estampa, una de las mejores de este burilista, es conocida por el Caballo de Moncada".

AEA, LXXIX, 315, JULIO-SEPTIEMBRE, 307-332, 2006, ISSN: 0004-0428 


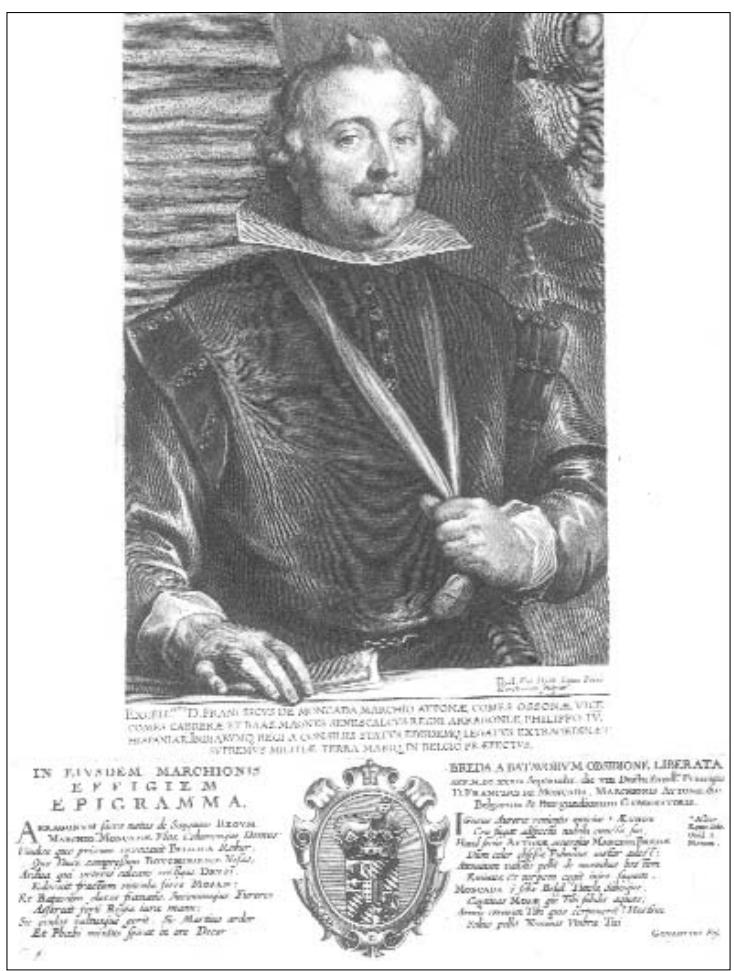

Figura 11. Lucas Vorsterman según A. van Dyck. Don Francisco de Moncada. Grabado.

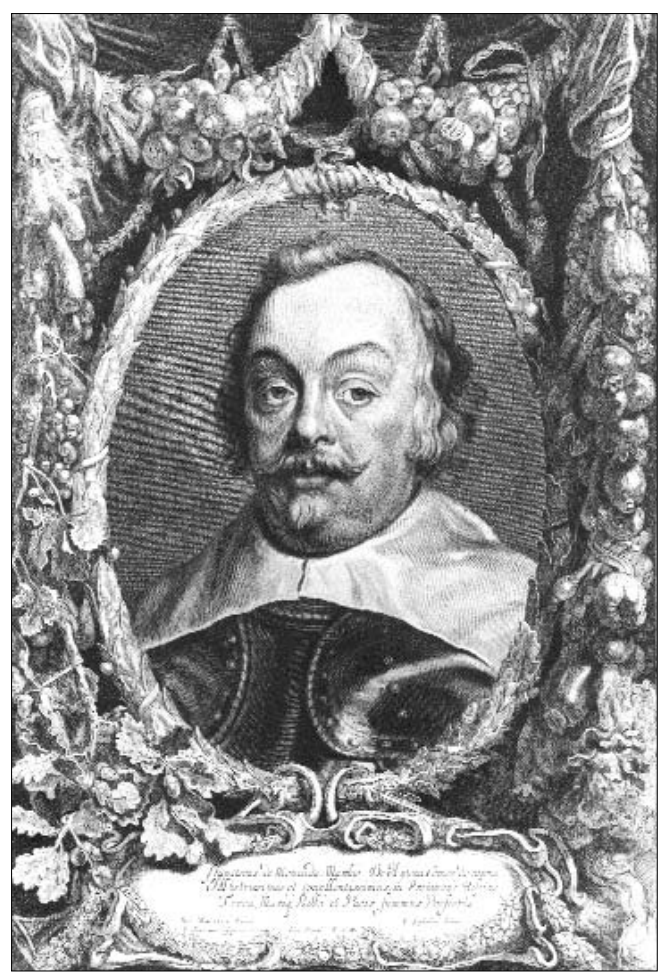

Figura 12. J. Suiderhoef y Peter Soutman según Van Dyck. Don Francisco de Moncada. Grabado.

consta en el inventario de $1648^{37}$. Realizado a la muerte de la Marquesa, dicho inventario es el primer documento que conservamos sobre la colección de los Haro, donde se registra la pintura: " $\mathrm{n}$ 1 102. -Mas otra pintura del Marques de aytona a caballo q tiene tres Baras y terçia de alto y tres menos quarta de ancho con su marco negro tassada en mill Rs q balen treinta y quatro mill mrs $34000 " 38$. No es extraño que no se cite el nombre de Van Dyck, pues sólo ocho pinturas constan en el mismo con atribución precisa ${ }^{39}$. La tasación (en maravedíes) corresponde a mil reales, que es el precio normal para un retrato de tales dimensiones y calidad.

Tras la muerte de Doña Catalina, la pintura pasó a la propiedad de su esposo, Don Luis, VI Marqués del Carpio; y así aparece registrada en su inventario post-mortem de 1661, conservado en los archivos de la casa de Alba en el Palacio de Liria de Madrid: " ${ }^{\circ}$ 187. -Otra del Marqs de Aytona acaballo, $3 \frac{1}{2} \times 2 \frac{1}{2}$ (Van Dyck)" 40 . (252 x $\left.210 \mathrm{~cm}\right)$. Los centímetros de diferencia entre

37 Así dice en su discurso: "Del inventario de bienes de Doña Catalina Fernández de Córdoba y Aragón, 1648, son las menciones de retratos de Carlos V y la Emperatriz; de Felipe IV a caballo; del Príncipe con unos perros; del Príncipe a caballo; y del Conde-Duque, a pie recibiendo la lanza del armero mayor; del Infante Don Fernando con halcón en la mano, y otro del mismo Infante a caballo, por Van Dyck, autor también del Marqués de Aytona a caballo, y por último, de la Duquesa de Milán y del Conde-Duque a caballo, pintado en Lisboa" [Berwick y Alba, Op. Cit. 1924, p. 109]

38 Burke, P. \& Cherry, P., Spanish Inventories, Collections of Paintings in Madrid, 1602-1755, Getty Information Institute, 1997, p. 446, $\mathrm{n}^{\circ} 102$

39 Cf. En Burke \& Cherry, Op. Cit. 1997, p. 437.

40 Burke, Op. Cit. 1984, II, p. 203. Estos documentos no datan del siglo XVII, sino que son copias de ellos y nuevas listas realizadas a principios del XIX. 
ambos inventarios indican que en el primero se incluyó el marco en las medidas. Tras la muerte de Don Luis, la pintura pasó a propiedad de Don Gaspar, figurando en su inventario de 1689, sin citar el nombre de su autor: " $\mathrm{n}$ " 110 -Otro Rettrato del Mrq. ${ }^{\mathrm{s}}$ de Aitona a Cavallo de poco mas de tres Varas de Caida y dos Varas y m. ${ }^{\mathrm{a}}$ de ancho en dos mill R. ${ }^{\mathrm{S}}$ 2000" 41 . Es lógico pensar que este retrato tasado en 2.000 reales sea el ejemplar de Alba, y que el tasado en 55.000 corresponda con el ejemplar del Louvre.

El lienzo del Museo San Pío V de Valencia [Fig. 2. Lienzo, 303.5 x 239.5 cm] es repetición de calidad del original del Museo del Louvre. Pensamos que debió estar en Valencia desde tiempos remotos, quizá en la propia familia del retratado. Su procedencia se documenta en la colección de Manuel Montesinos y Molina en el siglo XVIII (recogido en su catálogo de 1850: "Retrato de Don Francisco de Moncada, Marqués de Aytona"), y fue legado a la Academia de San Carlos por su herederos, Montesinos Checa y Trenor Montesinos, en 1941 ${ }^{42}$. Fue tenido por original por Tormo, Allende Salazar y Sánchez Cantón. De pincelada larga y fluida, este retrato de calidad no desmerece técnicamente del original del Louvre.

Una reducción del lienzo [Fig. 10. Lienzo, 56.2 x $46 \mathrm{~cm}]^{43}$, fue mencionada por Smith y Glück como modelleto preparatorio original del maestro ${ }^{44}$, pero se trata en realidad de una copia abocetada según el original del Louvre, adscrita a un seguidor de Van Dyck ${ }^{45}$. Otras copias se registran en diversas ventas a principios del siglo XIX y $\mathrm{XX}^{46}$.

\footnotetext{
41 Burke \& Cherry, Op. Cit. 1997, pp. 437-474, no 110.

42 Valencia, Museo de Bellas Artes San Pío V [Inv. no 494]. Véase la Bibliografía sobre este retrato: Catálogo de pinturas de la propiedad del coronel de Caballería D. Manuel Montesinos, Valencia, Imprenta del Presidio, 1850; Allende Salazar, J. \& Sánchez Cantón, F. J., Retratos del Museo del Prado, Madrid, 1919, p. 195; Tormo, E., "El centenario de Van Dyck en la patria de Velázquez", Boletín de la Sociedad Española de Excursiones, 1941, p. 148; Catálogo de los cuadros ingresados en el Museo de Bellas Artes de San Carlos, 1940; Catálogo de las obras que han ingresado en el Museo desde la liberación de la ciudad hasta el 31 de Diciembre de 1940, Museo Provincial de Bellas Artes de San Carlos, Exposición pública, 18-28 febrero, Valencia, 1941, nº 136, lám.; El Museo de Valencia renacido, 1947; Garín Ortiz de Torranco, F. M., Catálogo guía del Museo Provincial de Bellas Artes de San Carlos, 1955, p. 151; Gaya Nuño, J. A., Historia y Guía de los Museos de España, 1955, p. 727; Garín Ortiz de Torranco, F. M., "El Museo de Bellas Artes", Boletín de información municipal de Valencia, 50, Valencia, 1966, $2^{\circ}$ trimestre, p. 33; Díaz Padrón, M., La pintura flamenca del siglo XVII en España, Universidad Complutense, Madrid, Tesis Doctoral inédita, 1976, vol IV, p. 1166, fig. 562; Garín Llombart, F. V., Breve visita al Museo de Bellas Artes de Valencia, Valencia, 1977, p. 32; Sánchez Navarrete, M., El Museo de Bellas Artes I y II, Valencia, 1981, I, p. 26; Guía de Museos 1991, p. 213; Gil Salinas, R., Arte y coleccionismo privado en Valencia desde el siglo XVIII a nuestros días, Valencia, 1994, lám. portada y pp. 12, 171; Catalán Martí, J.I., "Anthony van Dyck: Retrat eqüestre d'en Francesc de Moncada, Marqués d'Aytona”, en Eixim al Carrer, Catálogo de exposición audiovisual, Valencia, 1995, p. 76-77, n 21; Company, X., Obras maestras del Museo de Bellas Artes San Pío V, Valencia, 1995, p. 112-113, no 49. A la altura de nuestra investigación no es fácil precisar la historia externa de este retrato. Cabe siempre la posibilidad de que el recorrido histórico que hemos trazado pudiera corresponder a esta pieza.

${ }^{43}$ Lienzo, 55,9 x 46,4 cm. Perteneció a Sir Henry Wellesley, barón Cowley, Ministro de Inglaterra en España (18111822); a la colección de Charles Sedelmayer de París; y posteriormente a W. Duschnitz; a Madame de Ferrière, Viena; pasó en venta al Hotel Drouôt (4-12-1920, C, como original de Van Dyck) y a la propiedad del Dr. L. C. Cohn-Collins, USA; a Luois S. Kaplan, USA; pasó en venta Christie's Londres, 23-03-1973, lot 68 (comprado por Witt); Sotheby's New York, 23-05-2001, lot 93; Christie's París, 26-06-2002, lot 16 (como seguidor de Van Dyck).

44 Smith, J., A catalogue raisonné, Londres, IX (suplemento), 1842, p. 371, no 13 (como Van Dyck); Glück, G., «Van Dyck's equestrian portraits », The Burlington Magazine, 1937, LXX, 410, p. 212, 216 (como Van Dyck); Glück 1931, p. 565, in $n^{\circ} 420$ (como Van Dyck).

45 Véase Vey, H., “Anton Van Dyck’s Olskizzen”, Bulletin des Musées Royaux des Beaux Arts de Bruxelles, 1956, p. 207, nota 46 (como copia de Van Dyck).

46 (1) « V. Dyck : Equestrian Portrait of Duke of Moncada, a fine Copy”, Vendido por Georges Graves a Buckman en 11.11 libras, Christie's Londres, 6/05/1803, lot 40. [The Index of Paintings Sold in the British Isles during the Nineteenth Century. Volume I. 1801-1805, Oxford, 1989, p. 276]. (2) "Copy after Van Dyck. The Marquess de Moncada", Christie's, 25-11-1826, vendido por 1.1 libras a F. (3) "Copy after Van Dyck. Duc de Moncada after van Dyck. Edward Foster,
} 
Géricault realizó una copia que sonserva el Stedelijk Museum de Ámsterdam ${ }^{47}$, y Watteau un dibujo a sanguina ${ }^{48}$.

Van Dyck retrató a Don Francisco de Moncada en otras ocasiones, y en el Museo del Prado conservamos un retrato de tres cuartos, adscrito al taller de Van Dyck, idéntico al original del Kunsthistorisches Museum de Viena ${ }^{49}$, que sirvió para el grabado de Lucas Vorsterman [Fig. 11], en el que se incluye su escudo de armas, y un poema en latín de Gaspar Gevartius que celebra la grandeza y las glorias militares de este general español ${ }^{50}$.

Pero el grabado más próximo a la pintura que estudiamos, donde el general está vestido con la misma armadura y cuello, y rodeado por una guirnalda de hojas y frutos, fue realizado por Jonas Suyderhoef y Peter Soutman [Fig. 12] ${ }^{51}$, igual que se ve en el retrato oval que estuvo en la colección Spencer Churchill de Northwick Park ${ }^{52}$.

JAHEL SANZSALAZAR

Londres, 15-03-1832, vendido por Robert Hamilton en 1.16 libras, y comprado por Hoorsley (¿). (4) Lienzo, 68 x 52 Copia de mala calidad, con las iniciales BV en el vértice inferior izquierdo, donde el general tiende la mano derecha señalando con el índice, en la colección Battistelli de Milán [Venta Lino Pesaro, Milán, 26-03-1914, nº 137].

47 Lienzo, 45 x $37 \mathrm{~cm}$. Ámsterdam, Stedelijk Museum. [L. Jonson, “A copy alter Van Dyck by Géricualt”, The burlington Magazine, CXII, 183, 1970, pp. 793797; G. Bazin, Théodore Géricualt, Paris, 1987, nº 300].

48 En colección Lousada. [K. T. Parker \& J. Mathey, Antoine Watteau... Oeuvre dessinée, París,1957, n 312].

49 Véase Díaz Padrón \& Padrón Mérida, Op. Cit. 1995, I, p. 504, nº 1502 (donde se recogen copias y variantes). Conocemos una registrada en la colección Mignot (6-12-1890, $\mathrm{n}^{\circ}$ 26); y otra (de busto) en venta G. V. Hallmann de Berlín (12-6-1918, no 162); además de dos tablas en grisalla, en colección privada británica (1981, con atribución a Daniel Mytens, 9 _ in. X 7 _ in. Foto Courtauld Institute, neg. B79/1347), y en el Hotel Drouôt de París con inscripción identificativa del retratado en el ángulo superior derecho (Tabla, 24,5 x 17,4 cm. 8-03-1982, $\mathrm{n}^{\circ} 77$, como atribuido a Van Dyck). Un retrato de busto (Lienzo, 60 x 57) se perdió en la II Guerra Mundial en Potsdam, Sanssouci [Zerstört. Entführt. Verschollen. Die Verluste der Preussischen Schlösser im Zweiten Weltkrieg, Potsdam, 2004, p. 515, nº GK I 12393].

50 A la derecha: "D. A. Van Dÿck Eques Pinxit./ LVorsterman sculpsit". Seguidamente, en cuatro líneas: "EXCELL.[MVS] D. FRANCISCVS DE MONCADA, MARCHIO AYTONAE, COMES OSSONAE, VICECOMES CABRAE ET BAAS, MAGNVS, SENESCALCVS REGNI ARRAGONIAE, PHILIPO IV. HISPANIAR INDIARVMQ.REGI A CONSILIS STATVS EIVSDEMQ LEGATVS EXTRAORDIN.ET SVPREMVS MILITIAE TERRA MARIQ IN BELGIO PRAEFECTVS". El poema de Gevartius conmemora el papel Moncada en el sitio de Breda: "IN EIVSDEM MARCHIONIS / EFFIGIEM / EPIGRAMA / ARRAGONVM sacro natus de Sanguine REGVM / MARCHIO MONCADAE. Flos, Columenque Domus: / Vindice quo priscum revocauit BELGICA Robur ; / Quo Duce compresum BOVCHINIENSE Nefas; / Ardua qui veteris calcans vestigia DRVSI, / Edocuit fractum vincula ferre MOSAM; / Et Batavum elatos fraenans, Suconumque Furores / Asseruit forti Regia iura manu; / Sic oculos vultusque gerit. Sic Martius ardor / Et Phoebi mixtus spirat in ore Decor". A la derecha del escudo: "BREDA A BATAVORUM OBSIDIONE LIBERATA / ANN. M.DC.XXXIV. Septebr. die VIII. Ductu Excell.mi Principis / D. FRANCISCI DE MONCADA, MARCHIONEIS AYTONAE, \&C. / Belgarvm \& Burgundionum Gubernatoris. / IGneus Aurorae venientis nuncius AETHON / Ceu fugat adspectu nubila cuncta suo / Haud secus AYTONAE generosus MARCHIO, BREDAE / Dum celer obsessa Fulminis instar adest; Attonitum validis pellit de moenibus hostern / Eminus turpem cogit inire fugam. / MONCADA ô felix Belgi Tutela, Salusque, / Captiuas MOSAE qui Tibi subdis aquas; / Armis cernenti Tibi quis certauerit Hostem / Solius pellit Nominis Vmbra Tui" [Vid. The New Hollstein Ducth \& Flemish Etchings Engravings and Woodcuts. 1450-1700. Anthony Van Dyck, Part I, 2002, p. 119, nº 26/VII].

51 En la cartela de la parte inferior se lee la siguiente inscripción: "franciscus de Moncada, Marchio De Aÿtona, Comes de ossona / Illustrisimus et excellentisimus, in Prouincÿs Belgicis / Terra, Mariq, Belli et Pacis summus Prefectus". A la izquierda: Ant. Van Dyck Pinxit. Derecha: I Suÿderhoef Sculpxit. Abajo a la izquierda: P. Soutman Effigiauit et Excud. En medio: Cum Priuil S. C. M. [Vid. New Hollstein, Op. Cit. 2002, Part IV, p. 107, n 271, p. 121].

52 Lienzo, 66,7 x $52 \mathrm{~cm}$. Venta Spencer Churchill (Northwick Park), Christie's Londres, 29-10-1965, n⿳亠 36 (como Van Dyck) [foto Courtauld Institute, Copia de busto en formato oval. Lienzo, 66,7 x $52 \mathrm{~cm}$. Colección Spencer-Churchill, Northwick Park, Cat. 1921, no 127; Venta Christie's Londres, 29-10-1965, nº 36 (como Van Dyck). Foto Courtauld Institute, Londres, neg. Nr. B 66/892]. 